\title{
Dominating Molecules in the Photospheres of Cool Stars
}

\author{
Uffe Gråe Jørgensen
}

Niels Bohr Institute, Blegdamsvej 17, DK-2100 Copenhagen, Denmark

\section{Introduction}

Molecular data bases (including very different numbers of molecular lines, and based on computations spanning a wide range in quality) have been used in the construction of models of the stellar atmospheric structure, and effects of various molecules on the stellar structure and evolution have been described in the literature. A systematic study showing which molecules are of importance in which types of stars is, nevertheless, still lacking, and the line lists used in various model computations necessarily reflect what was at hand at the time of computation rather than a systematic effort to solve the molecular opacity problem. A pioneering investigation was presented in two extensive papers by Tsuji (1964, 1973) where the foundation of the reaction scheme used in most models today was laid down. Later Tsuji (1986) has given a review of the existing work on molecules known in stars, and Johnson (1986) and Gustafsson (1989) have touched upon the same subject in reviews covering a broader range of stellar aspects. Jørgensen (1992) has recently summarized the existing molecular data (and discussed the methods used) available for model atmosphere construction.

In the present review I attempt to present a systematic analysis of the effect of the most abundant molecules in cool stars, and to touch upon what can be the most important missing molecular data for further progress in the field. For this purpose, I have computed about 150 new model atmospheres where various molecules have been included in, or excluded from, the adopted opacity in a systematic way. The models are based on a recent version (Jørgensen et al. 1992) of the Marcs code (Gustafsson et al. 1975) with molecular opacities (described further in section 4) from $\mathrm{CO}, \mathrm{CN}, \mathrm{C}_{2}, \mathrm{TiO}, \mathrm{HCN}, \mathrm{C}_{2} \mathrm{H}_{2}, \mathrm{C}_{3}$, and $\mathrm{H}_{2} \mathrm{O}$ considered in the computations. The code, with the input data used, is particularly tuned for computations of giant stars (stars with low gravity), and the emphasis in the present review will therefore be on red giants, but dwarf models will be computed for comparison purposes and for evaluation of trends. Whereas most of the results for the giant stars presented in this review are as reliably as is possible today, the results for the dwarfs $(\log (g)=+4.5)$ are to be considered as more qualitative in nature. A thorough description of the dwarf 
stars and opacity problems particular to these are described elsewhere in this book by Borysow, Liebert, Scholz \& Wehrse, and by Tsuji.

A stellar atmosphere is the outer, observable layer of a star - as opposed to the invisible stellar interior. The photosphere is the (lower) layer of the atmosphere where most of the visible (and infrared) part of the stellar spectrum is produced, and where the temperature decreases outward from the star. Often the atmosphere is used synonymously with the photosphere because only very few models exist for the layers above the photosphere. The effective temperature, $T_{\text {eff }}$, is an "average" temperature of the photosphere, but there are both (deeper) layers in the photosphere with temperatures much higher than $T_{\text {eff }}$ and (higher) layers in the photosphere with temperatures somewhat below $T_{\text {eff }}$. Also the surface gravity ( $g$, here referred to in cgs units), the metallicity $Z$ (the mass fraction of the elements heavier than helium) and the $\mathrm{C} / \mathrm{O}$ ratio are of vital importance for the atmospheric structure. The basic stellar parameters in the models computed here consist of various combinations of $T_{\text {eff }}=4500,3500$, $3100,2800,2500 \mathrm{~K} ; \log (g)=-0.5,+0.5,+1.5,+4.5 ; \mathrm{C} / \mathrm{O}=0.43,0.86,0.92$, $0.95,0.98,1.0,1.01,1.02,1.05,1.35,2.0$, and $Z=Z_{\odot}$ (i.e., the solar abundance except for carbon).

\section{Stellar Evolution into the "Molecular Regime"}

The majority of stars end their life in the red giant phase where the outer parts expand and cool, while the interior slowly transforms into a hot, compact object (a white dwarf) of material that will slowly cool and undergo no further nuclear processing. While the stars are red giants they will, for the first time in their life, mix nuclear processed material from the interior to the surface (see e.g., Iben \& Renzini 1983 and Lambert this volume). The cooler and more luminous they get the more of this material will be blown into space (e.g., de Jager et al. 1988), and in this way the gas and dust clouds, that new stars and planets are created from, will slowly be more and more enriched with nuclear processed material from cool red giants. Today it is even possible to trace some of the material that our own solar system was created from back to various types of red giants (e.g., Anders \& Zinner 1993).

The Sun will become a red giant in about 7 billion years from now, and during about 200 million years the Sun will develop from a phase where it is $3500 \mathrm{~K}$ (and has 1000 times its present luminosity) to a final stage another 5 times more luminous and with $T_{\text {eff }} \approx 2500 \mathrm{~K}$ (Jørgensen 1991). It is in this interval of effective temperature that molecules dominate the structure of the stellar atmosphere, and I will here call it the "molecular regime" of stellar evolution. In stars warmer than $3500 \mathrm{~K}$, the atomic lines become of increasing importance relative to the molecular lines, although a proper study has never been performed of where exactly the transition between the "atomic regime" and the "molecular regime" is (see Seaton this volume). There are also stars assumed to be cooler than $2500 \mathrm{~K}$, but we have no reliable models of them yet. Dust may be an important opacity source in such stars (see Alexander \& Ferguson and Sedlmayr, 
this volume). Stars tend to lose the bulk of their mass to the interstellar space while they are in the molecular regime - perhaps even triggered by the radiative pressure on the molecules (Jørgensen \& Johnson 1992). The Sun is expected to lose $50 \%$ of its present mass while $2500 \mathrm{~K}<T_{\text {eff }}<3500 \mathrm{~K}$.

At far lower luminosities there is another important group of stars within the same temperature interval. They are the $\mathrm{M}$ dwarfs and the brown dwarfs. They spend basically all of their lifetime in the molecular regime. The brown dwarfs may be so numerous that they contribute significantly to the "missing" mass in the universe, and the group of $M$ dwarfs house some of the oldest stars in existence. Also the coolest white dwarfs - remnants of a higher mass generation of stars formed in the very early days of our Galaxy - are in this temperature interval (see Liebert this volume and Thejll this volume). Analysis of the spectrum of these more compact objects involve problems that are very different from those found in the red giants, but common for all the stars in the molecular regime is that the structure in the layers that we can observe is dominated by molecular opacities. Further progress in our understanding of their role in the evolution of the universe is therefore dependent on development in our knowledge of the molecules that dominate their atmospheric opacity.

\section{Which Molecules Dominate the Stellar Opacity?}

In stars of solar abundance hydrogen and helium accounts for $98 \%$ of the mass, but the only stable molecule formed from these atoms is $\mathbf{H}_{2}$. For all cool stars, $\mathrm{H}_{2}$ is the most abundant molecule throughout the atmosphere. If $\mathrm{H}_{2}$ was dipole active in its ground state, the study of molecular absorption in stars would be completed by the study of molecular hydrogen. Molecules made up of combinations of $\mathrm{H}, \mathrm{C}, \mathrm{N}$, and $\mathrm{O}$ (in the Sun, CNO accounts for $86 \%$ of the atoms heavier than $\mathrm{He}$ ), or even more rare elements, are much less abundant in the stellar atmosphere. However, they have so much stronger absorption coefficients that their resulting opacity in the visual and near infrared spectral region (where cool stars transmit their energy) is orders of magnitude bigger than that of $\mathrm{H}_{2}$. For example, in a red giant of $3500 \mathrm{~K}$ and solar elemental composition there are 1 million $\mathrm{H}_{2}$ molecules for each $\mathrm{TiO}$ molecule, but still TiO dominates the opacity.

The second most abundant molecule in nearly all cool stars is CO, because of its very high dissociation energy and because of the high cosmic abundance of carbon and oxygen. In the Sun, oxygen accounts for $55 \%$ of all the atoms heavier than helium, and carbon for $52 \%$ of the rest (Anders \& Grevesse 1989). In contrast to the Earth's atmosphere, $\mathrm{CO}$ is much more abundant than $\mathrm{CO}_{2}$ in red giants, which is an effect of the extremely low pressure in their atmospheres. For the same reason molecules like $\mathrm{NH}_{3}$ and $\mathrm{CH}_{4}$, that are very abundant in planetary atmospheres, do not seem to form in red giants. For the less studied "high-pressure" stars like brown dwarfs and cool white dwarfs these molecules may be important (see Tsuji this volume).

$\mathrm{CO}$ has its vibration-rotation spectrum in a region $(1-5 \mu \mathrm{m})$ where cool stars emit a considerable fraction of their energy, but although its absorption coef- 
ficient is much higher than that of $\mathrm{H}_{2}$ (i.e., the quadrupole transitions) in the same region, its absorption is still weak compared to other molecules made of $\mathrm{H}, \mathrm{C}, \mathrm{N}, \mathrm{O}$ and heavier elements, and particularly its absorbtion is discrete (i.e., concentrated to relatively few but strong lines) so that the stellar flux can escape the star between the lines. This effect drastically decreases the importance of CO compared to what one might have guessed based on its high partial pressure and relatively high integrated absorption coefficient. Only in situations where there are no or only few other molecules, the effect of $\mathrm{CO}$ may be substantial. In the Sun, where the temperature throughout the atmosphere is high compared to the stars we discuss in this review, $\mathrm{CO}$ will be the only molecule of importance, and its effect is presumably to form clouds of cool gas in an otherwise warm solar atmosphere, just as it would cool and contract the entire atmosphere of a red giant if it was the only molecule to form in such stars, as we will see in the following sections.

In a number of cool stars (but not all, as will be seen below) the group of the most abundant molecules after $\mathrm{CO}$, consists of $\mathrm{N}_{2}, \mathrm{CS}$, and $\mathrm{OH} . \mathrm{N}_{2}$ is dipole inactive in its ground state, and can (just as $\mathrm{H}_{2}$ ) be excluded from the opacity computations (but must obviously be taken into account in the molecular equilibrium computations). CS has a discrete absorption structure, just as CO, and usually a partial pressure 2 to 3 orders of magnitude lower than that of $\mathrm{CO}$. Its opacity has been included in recent model atmosphere computations by "the Indiana group" (Brown et al. 1989) based on a line list of 35000 lines compiled by Piñeiro et al. (1987), but it has never been included in the models computed with the Marcs program or in the "Kurucz-models" (Kurucz 1979) based on the "Smithsonian data base" (Kurucz this volume). The effect of this molecule on the model structure has not been described in the literature, but it is an opacity that deserves much more attention. CS is also abundant in circumstellar envelopes and in the stellar wind (see Hinkle this volume and Olofsson this volume). OH is very abundant in certain oxygen-rich red giants, and it is often observed as a maser, too. It is an illustrative example of a very abundant molecule where big confusion about its role still exists. It has never been included in computations with the Marcs code, it is listed with 330000 lines (although most in the UV where they will be without effect for cool stars) in the Smithsonian data base, and it has been included with less than $1 \%$ of this number of lines in the Indiana group computations. No study of its role for the atmospheric structure exists. Other molecules that may have exceptionally high partial pressures in some model atmospheres include $\mathrm{SiO}, \mathrm{H}_{2} \mathrm{O}$, and $\mathrm{NO}$.

The molecules presumed to have the biggest effect on the model structure are generally those in the fourth most abundant group (after $\mathrm{H}_{2}, \mathrm{CO}$, and $\mathrm{N}_{2} / \mathrm{CS} / \mathrm{OH}$ ) and their partial pressures are typically, say, 7 orders of magnitude below that of $\mathrm{H}_{2}-$ a tiny, tiny fraction of the total gas pressure. Due to their rarity the balance between them is easily shifted, and therefore small errors in the adopted molecular absorption coefficient can result in big adjustments of the model structure, via adjustments in the molecular equilibrium. This is one of the reasons why high accuracy and completeness is required in the molecular 
data. If the electronic transitions of $\mathrm{CO}$ (and/or $\mathrm{H}_{2}$ ) had been in the spectral region where cool stars emit the bulk of their energy, the situation would have been very much simpler (and of course also relatively dull).

An extreme example of the effect of incompleteness in the molecular data can be examined by setting certain of the molecular absorption coefficients to zero (more realistic examples will be considered in a later section). Consider first a carbon star model with $T_{\text {eff }}=3500 \mathrm{~K}$ and only continuum sources in the opacity. This model turns out to be completely unaffected by the possible inclusion of the opacity of polyatomic molecules $\left(\mathrm{HCN}, \mathrm{C}_{2} \mathrm{H}_{2}\right.$, and $\left.\mathrm{C}_{3}\right)$. A similar model including continuum sources, and now also the opacity of the diatomics $\mathrm{CO}, \mathrm{C}_{2}$ and $\mathrm{CN}$, expands with $25 \%$ in size (and the gas pressures in the surface layers decrease with a factor of 30 ) if the opacitiy from the polyatomics is introduced. The large difference in the way the two models react to the inclusion of the opacity from the polyatomics, is due to the cooling effect of $\mathrm{CO}, \mathrm{C}_{2}$, and $\mathrm{CN}$, which gives rise to a much larger partial pressure of the polyatomic molecules in the model which considers also opacity from $\mathrm{CO}, \mathrm{C}_{2}$, and $\mathrm{CN}$. The lesson from this is clear: it is in principle not possible to say which molecules will dominate the opacity before all molecular opacities have already been included. The inclusion of additional opacity sources (or improved completeness in the line list of already included opacities) may change the atmospheric structure in such a way that other molecules suddenly become dominant.

Also due to the small partial pressure of the "opacity-strong" molecules, small changes in the most abundant atoms can cause very big changes in the molecular equilibrium. The ratio that is most important for such changes is the $\mathrm{C} / \mathrm{O}$ ratio (but also the $\mathrm{Si} / \mathrm{S}$ ratio can effect the spectrum drastically), and it causes the distinction between K- or M-type (oxygen-rich) red giants, S-type stars, and carbon stars, where different molecules will dominate the opacity, and which will therefore be discussed individually below.

During the late phases of stellar evolution carbon and s-process elements are created in the stellar interior and mixed into the visible layers. In the Sun (where no nuclear processed material has been mixed to the surface) $\mathrm{C} / \mathrm{O}=0.43$, which is therefore assumed to be the "starting condition" for "normal" stars. When enough carbon is mixed to the surface during the red giant phase, the ratio $\mathrm{C} / \mathrm{O}$ approaches unity, and the chemical balance shifts drastically from oxygen bearing molecules to carbon bearing molecules, because either all the carbon or all the oxygen is bound in $\mathrm{CO}$. The molecules that dominate the structure in oxygen and in carbon-rich stars are therefore completely different from one another. In high metallicity environments, like our own galaxy, oxygen-rich red giant stars are much more common than carbon stars, but in metal deficient environments the opposite is true (Richer \& Westerlund 1983, Jørgensen \& Johnson 1992).

A good feeling about which molecules should be expected to be found in stellar atmospheres can be obtained by looking at the dissociation energies of various molecules. Those with the highest dissociation energies will form first and thereby use up all of the available material of the least abundant atom in the molecule. Some of the diatomic molecules with highest dissociation energies 
Table 1. Dissociation energy (from Tsuji (1964) except for CN from Costes et al. (1990) and TiO from Colket (1984)) of some important molecules, and the elemental abundance (in units of atoms per $10^{6} \mathrm{Si}$ atoms; from Anders \& Grevesse (1989)) in the solar system (numbers in parenthesis are exponents of 10 ).

\begin{tabular}{lrrrrrrrrrr}
\hline \hline molecule: & $\mathrm{CN}$ & $\mathrm{HCN}$ & $\mathrm{C}_{2}$ & $\mathrm{C}_{2} \mathrm{H}$ & $\mathrm{C}_{2} \mathrm{H}_{2}$ & $\mathrm{C}_{3}$ & $\mathrm{C}_{3} \mathrm{H}$ & $\mathrm{C}_{4}$ & $\mathrm{C}_{5}$ & $\mathrm{CH}$ \\
$\mathrm{D}_{0}(\mathrm{eV}):$ & 7.77 & 4.94 & 6.12 & 5.72 & 4.95 & 7.74 & 4.92 & 5.21 & 7.41 & 3.47 \\
\hline molecule: & $\mathrm{MgH}$ & $\mathrm{CaH}$ & $\mathrm{SiC}$ & $\mathrm{SiC}_{2}$ & $\mathrm{CH}_{4}$ & $\mathrm{NH}$ & $\mathrm{NH}_{3}$ & $\mathrm{NO}$ & $\mathrm{CO}$ & $\mathrm{CO}_{2}$ \\
$\mathrm{D}_{0}(\mathrm{eV}):$ & 1.97 & 1.75 & 4.5 & 8.7 & 4.38 & 3.8 & 4.52 & 6.50 & 11.09 & 5.45 \\
\hline molecule: & $\mathrm{H}_{2} \mathrm{O}$ & $\mathrm{OH}$ & $\mathrm{SiO}$ & $\mathrm{TiO}$ & $\mathrm{TiO}_{2}$ & $\mathrm{VO}$ & $\mathrm{ZrO}$ & $\mathrm{ScO}$ & $\mathrm{YO}$ & $\mathrm{LaO}$ \\
$\mathrm{D}_{0}(\mathrm{eV}):$ & 5.10 & 4.40 & 8.1 & 7.95 & 6.7 & 6.4 & 7.8 & 6.9 & 9.0 & 8.15 \\
\hline \hline element: & $\mathrm{H}$ & $\mathrm{C}$ & $\mathrm{N}$ & $\mathrm{O}$ & $\mathrm{Mg}$ & $\mathrm{Si}$ & $\mathrm{Fe}$ & $\mathrm{S}$ \\
abundance: & $2.79(10)$ & $1.01(7)$ & $3.13(6)$ & $2.38(7)$ & $1.07(6)$ & $1.00(6)$ & $9.00(5)$ & $5.15(5)$ \\
element: & $\mathrm{Ca}$ & $\mathrm{Ti}$ & $\mathrm{V}$ & $\mathrm{Sc}$ & $\mathrm{Zr}$ & $\mathrm{Y}$ & $\mathrm{La}$ & & \\
abundance: & $6.11(4)$ & $2.4(3)$ & $2.93(2)$ & $3.42(1)$ & $1.14(1)$ & 4.64 & $4.46(-1)$ & \\
\hline \hline
\end{tabular}

are listed in Table 1. More complete lists can be found in Tsuji $(1964,1973)$, Huber \& Herzberg (1979), and in Chase et al. (1984; the JANAF tables).

\section{The SCAN data base of molecular lines}

The original computations with the Marcs code (Gustafsson et al. 1975) included about 50000 (observed) lines from various diatomic hydrides, and were tuned particularly for computation of models in the range of $T_{\text {eff }}$ approximately between $3700 \mathrm{~K}$ and $6000 \mathrm{~K}$. In more recent computations of cool star models, these lines are no longer included, but in stead a more complete line list, which excludes some of the original hydrides, is used. This fact does not reflect a knowledge of, say, $\mathrm{CH}, \mathrm{MgH}$ and $\mathrm{NH}$ being unimportant, but rather the recognition of the overwhelming importance of completeness in the line list of the molecules. Inclusion of a few lines for an additional molecule may give the false impression that this molecule is "considered". The most complete computations with the Marcs code, as concerns the molecular opacities, are those of Jørgensen et al. (1992) for the carbon-rich models, and those of Plez et al. (1992) and Jørgensen (1993) for the oxygen-rich stars.

These models include the opacities of $\mathrm{CO}$ and $\mathrm{C}_{2}$ from Querci et al. (1974) and the opacities of $\mathrm{CN}, \mathrm{C}_{3}, \mathrm{C}_{2} \mathrm{H}_{2}, \mathrm{HCN}$, TiO and $\mathrm{H}_{2} \mathrm{O}$ from what we now call the SCAN data base. These opacities are produced and described by Jørgensen et al. (1985) for HCN, by Jørgensen et al. (1989) for $\mathrm{C}_{3}$, by Jørgensen \& Larsson (1990) for CN, by Jørgensen (1993) for TiO, and by Jørgensen \& Jensen (1993) for $\mathrm{H}_{2} \mathrm{O}$. The $\mathrm{TiO}$ opacity represents an updating and extension of the original list by Krupp et al. (1978). The lists for $\mathrm{CN}, \mathrm{HCN}, \mathrm{C}_{3}$ and for $\mathrm{H}_{2} \mathrm{O}$ are based on full ab initio computations of the dipole moment and potential energy surfaces by use of the CASSCF theory (see Langhoff \& Bauschlicher this volume and 
Malmqvist this volume). The potential energy surface and the solution of the Schrödinger equation for the $\mathrm{H}_{2} \mathrm{O}$ computations have been improved by use of the MORBID theory (see Jensen this volume), and a similar update for the HCN molecule is in progress. The opacity of $\mathrm{C}_{2} \mathrm{H}_{2}$ is constructed from observational data and some simplified assumptions about the unobserved combination bands based on experience with other molecules (unpublished work, but the method has been described in some detail by Jørgensen 1990). A SCAN line list for $\mathrm{CH}$ will soon be available too (Jørgensen \& Larsson, in preparation), and work on $\mathrm{FeH}, \mathrm{SiC}_{2}, \mathrm{CaH}$, and other small molecules is under consideration. In total the SCAN data base contain about 60 million lines (identification, frequency, excitation energy, and line strength) from 7 of the most important molecules in stellar atmospheres, and many more will hopefully be added in the future.

One of the most important experiences we have got from our construction of the SCAN data base is that completeness of the line lists used in the opacity construction is of overwhelming importance. With the strongly increased computer capacity over the last, say 10 years, it is today affordable, for small molecules, to compute the complete set of lines between basically all eigenstates with energies up to very close to the dissociation energy. Most data in use have a cut off at some arbitrary energy level, or $(\mathrm{v}, \mathrm{J})$-level, chosen to make the computation and the data handling affordable in terms of computing time and required data storage space. For this reason it must be expected that there is quite a lot of work ahead in re-computing the data for a number of diatomic and other small molecules where some data already exist.

In our computation of the "red" system of CN (Jørgensen \& Larsson 1990, see also Larsson this volume) we introduced, as a measure of the completeness of the line list, the ratio of the partition functions obtained by summation of all included eigenstates and by summation of all possible states, respectively. The method has been developed further in our work on $\mathrm{H}_{2} \mathrm{O}$ (Jørgensen \& Jensen 1993, Jørgensen et al. 1994). In our work on CN we found that $99.9 \%$ of the partition function was included in our computation for temperatures up to $5000 \mathrm{~K}$. About $40 \%$ of the missing $0.1 \%$ of the population was due to exclusion of vibrational levels with $\mathrm{v}>30$ (up to the dissociation energy corresponding to $\mathrm{v} \approx 60$ ), and about $60 \%$ was due to the exclusion of transitions with lower levels in the third electronic state (the B level). Experiments with use of the SCANCN data, have shown 10 times higher opacity in the visual region compared to previous estimates of the CN "red" opacity.

In our work on $\mathrm{CN}$, all lines with $\mathrm{J}$ less than a high value, $\mathrm{J}_{\max }$, was included on the tape, but for $\mathrm{H}_{2} \mathrm{O}$, where space demands a more careful evaluation, we computed the line intensity at a reasonably high temperature and included a line on the list only if its intensity was above a given pre-specified value. Ideally, lines with such high values of $J$ should be included so that the energy of the level $\left(\mathbf{v}, \mathbf{J}_{\max }\right)$ is (for each $\mathbf{v}$ ) equal to the dissociation energy. In practical terms, it can be problematic to include the rotational levels up to the dissociation energy, because the molecular constants often are insufficiently known, and because it involves unreasonably many lines (of doubtful effect). Nevertheless, the inclusion 
of high values in $\mathbf{J}$ is less critical than the inclusion of high values in $\mathbf{v}$, because the integrated band intensity is often known, and one then just has to make sure that the sum of all the intensities of all lines is equal to the integrated band intensity within a specified accuracy. This method was used by Jørgensen et al. $(1985,1989)$ in the computation of the absorption coefficient of $\mathrm{HCN}$ and $\mathrm{C}_{3}$, respectively. The vibrational transition moment was computed between all the vibrational eigenstates, without consideration of rotation but in a full quantum mechanical treatment. In our original use of the (simplified) vibrational transition moments for HCN (Eriksson et al, 1984), we estimated how much of the integrated band intensity was missing when computing to a given (affordable) value of $\mathrm{J}_{\max }$ and then distributed the rest as a continuum opacity, but with the increased computer capacity of today we simply compute each band by including sufficiently high values of $J$ till a given fraction (e.g., 99.9\%) of the band intensity is included. Typically such computations lead to about 10 million lines per molecule, which can reasonably be stored on tapes and handled on disks, but with a fast computer the line list can also be generated directly from the band list (for linear molecules) and stored in the form of an opacity sampling (OS) or an opacity distribution function (ODF) within a few CPU hours of computing.

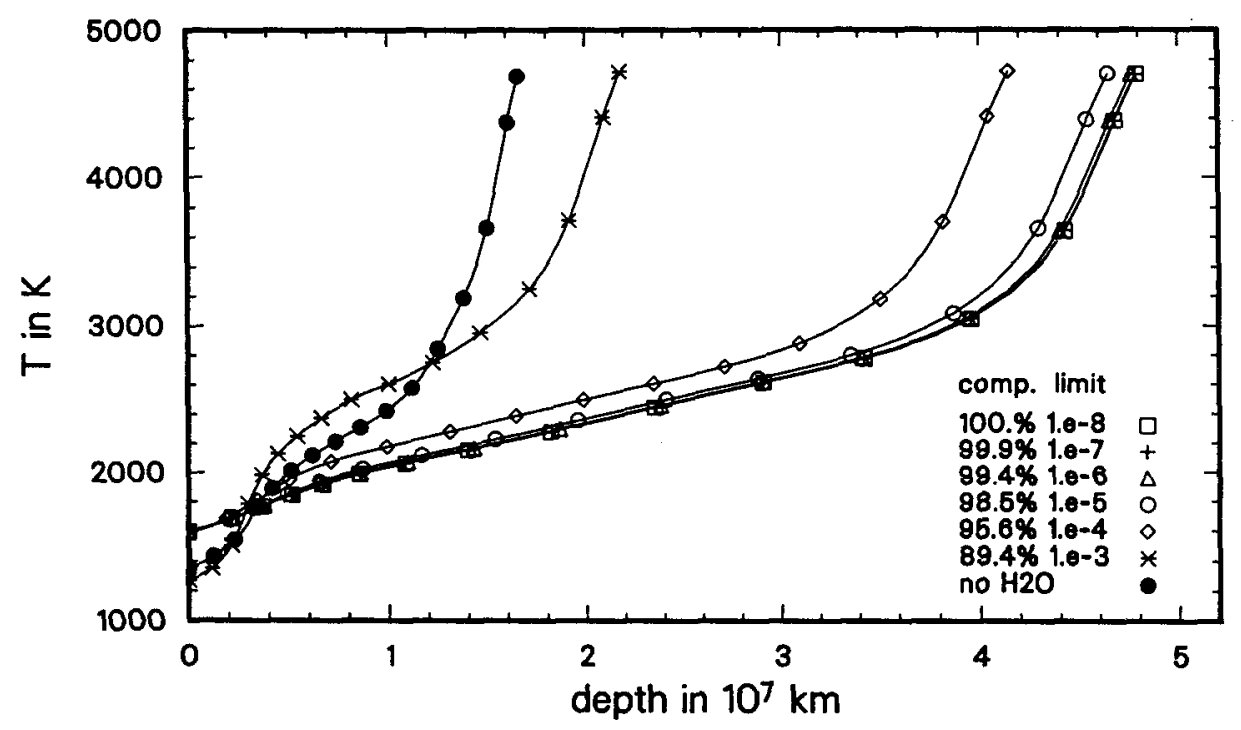

Fig. 1. The geometrical size of an oxygen-rich model atmosphere of $T_{\text {eff }}=2800 \mathrm{~K}$, $\log (g)=-0.5, \mathrm{C} / \mathrm{O}=0.43$ when various degrees of completeness in the opacity of the water molecule is considered. 
For asymmetric top molecules, such as $\mathrm{H}_{2} \mathrm{O}$, having both $\mathrm{J}$ and $\mathrm{K}$ rotational quantum numbers, the total number of lines easily becomes billions. The handling of this big number of lines is both difficult in computing time and disk space, and is, fortunately, without much meaning. On the other hand the computation of line intensities from the vibrational intensities is much more time consuming for an asymmetric top molecule (like $\mathrm{H}_{2} \mathrm{O}$ ) than for a linear molecule (like $\mathrm{HCN}$ ), and it is not affordable to re-compute the lines each time a new OS or ODF is desired (hundreds or thousands of CPU hours are needed on a medium size computer depending on the required accuracy). Therefore the effect of still weaker lines on the stellar atmospheric structure has been explicitly studied for $\mathrm{H}_{2} \mathrm{O}$ by including only lines stronger than a given threshold limit, $S_{\mathrm{lim}}$, which was tested as both $10^{-3} \mathrm{~km} / \mathrm{mol}, 10^{-4} \mathrm{~km} / \mathrm{mol}, 10^{-5} \mathrm{~km} / \mathrm{mol}$, etc to $10^{-8} \mathrm{~km} / \mathrm{mol}$ (Jørgensen et al. 1994). The value of $S_{\text {lim }}$ necessary for convergence in the model structure depends not only on the basic stellar parameters (a lower value of $S_{\mathrm{lim}}$ is required for high gravity objects and/or lower values of $\left.T_{\text {eff }}\right)$, but also on the quality of the other opacities included. For a test model of $T_{\text {eff }}=2800 \mathrm{~K}$ without $\mathrm{TiO}$, the difference in model temperature in the surface layer when $S_{\lim }$ (for water) was $10^{-6}$ and when it was $10^{-8}$, was $20 \mathrm{~K}$, whereas the difference was only $6 \mathrm{~K}$ for corresponding models with $\mathrm{TiO}$ included. The more complete the total set of opacities of the molecules is, the less important it is whether the opacity for one of the molecules is computed to the highest possible accuracy or not. The more recent opacities in the SCAN data base are accompanied by a completeness analysis which gives an impression of how big a fraction of the opacity is included. This is important not only for the model structure, but also for the continuum drawing in spectral analysis.

\section{Oxygen-Rich Giant and Dwarf Stars}

The oxygen-rich stars are the most common cool stars in the solar neighbourhood, and therefore also the most well studied. Several of the bright stars we see with the naked eye on the night-sky are cool oxygen-rich red giants. The molecular opacity of these stars is dominated by $\mathrm{H}_{2} \mathrm{O}, \mathrm{TiO}$, and $\mathrm{CO} . \mathrm{CO}$ and $\mathrm{TiO}$ are important opacity sources throughout the "molecular regime", but $\mathrm{H}_{2} \mathrm{O}$ is the dominant molecular opacity source for the cooler giants, whereas $\mathrm{CN}$, in oxygen-rich stars, only affects the structure of the stars warmer than $T_{\text {eff }}=3500$ $\mathrm{K}$. For example, the partial pressure of $\mathrm{CN}$ is 7 orders of magnitude below that of $\mathrm{TiO}$, at $\tau_{\mathrm{Ross}}=10^{-2}$ in a $T_{\mathrm{eff}}=2500 \mathrm{~K}$ model of solar abundance, whereas it is as abundant as TiO for a $T_{\text {eff }}=3500 \mathrm{~K}$ model. For a similar model of $T_{\text {eff }}$ $=4500 \mathrm{~K}, \mathrm{CN}$ is the most abundant molecule in all layers below $\tau_{\text {Ross }}=10^{-4}$, but at those temperatures atomic lines and continuum sources may dominate the atmospheric opacity, and the relative contribution of molecules and atoms has not been thoroughly studied yet. The ratio between the partial pressures of $\mathrm{CO}$ and $\mathrm{TiO}$ is almost constant, $\mathrm{P}(\mathrm{CO}) / \mathrm{P}(\mathrm{TiO}) \approx 10^{4}$, throughout the atmosphere, as is also seen in Fig. 2. The ratio between the partial pressure of $\mathrm{H}_{2} \mathrm{O}$ and that of $\mathrm{TiO}$ (or $\mathrm{CO}$ ), on the other hand, increases rapidly for models cooler 
than $T_{\text {eff }} \approx 3000 \mathrm{~K}$. At $T_{\text {eff }}=3100 \mathrm{~K}$ and $\log (g)=-0.5$, the partial pressure of $\mathrm{H}_{2} \mathrm{O}$ equals that of $\mathrm{TiO}$ in the surface $\left(\log \tau_{\mathrm{Ross}}=-5.5\right)$, but already for $T_{\text {eff }}=$ $2800 \mathrm{~K}$ the partial pressure of $\mathrm{H}_{2} \mathrm{O}$ in the surface is nearly 4 orders of magnitude bigger than that of TiO.

When compared to a model where only the continuum opacities are included, the effect of $\mathrm{CO}$ is mainly to cool the surface layers and to contract the whole atmosphere. The effect of $\mathrm{TiO}$ alone is to cool the surface layers (and to create a back-warming in the deeper layers) and the effect of $\mathrm{H}_{2} \mathrm{O}$ is mainly to expand the atmosphere. In combination the molecules may, however, react in a more complex manner, and $\mathrm{TiO}$ is usually considered a heating agent (for the surface layers too) because models with continuum sources, $\mathrm{CO}, \mathrm{CN}$, and $\mathrm{H}_{2} \mathrm{O}$ included in the opacity generally are cooler than models including also TiO. The effect of these molecules, individually and together, on the structure of a typical red giant is shown in Fig. 2.

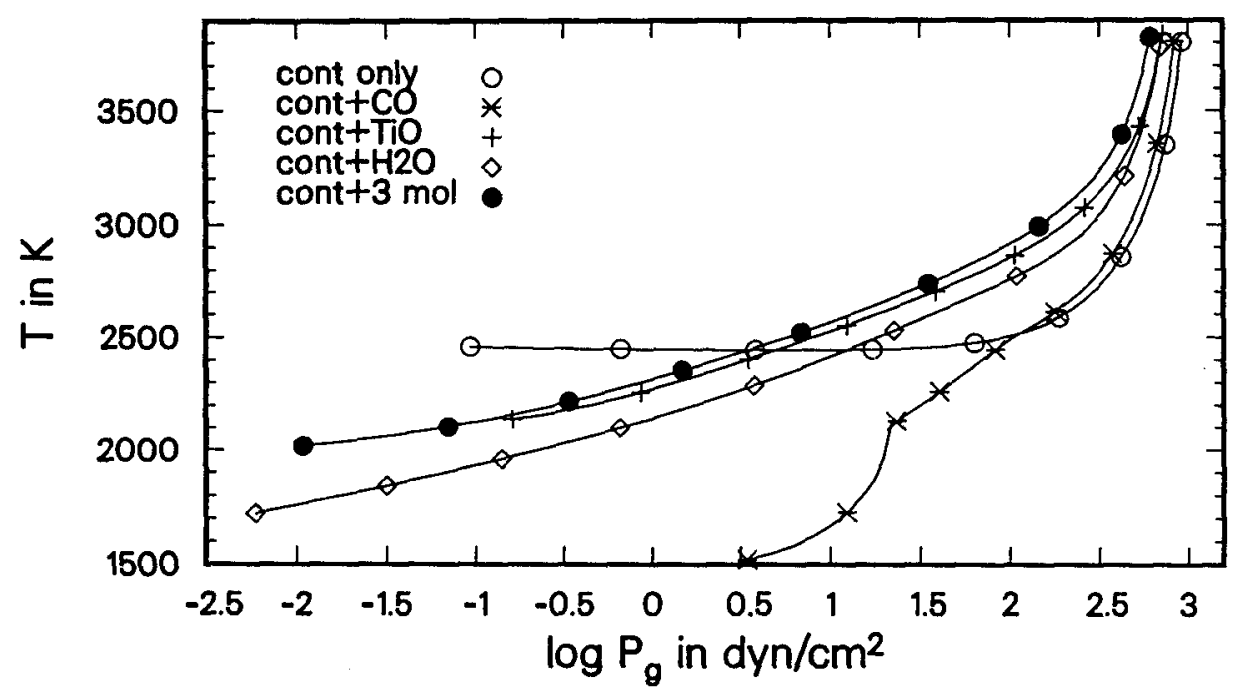

Fig. 2. Effects of $\mathrm{CO}$, TiO, and $\mathrm{H}_{2} \mathrm{O}$ on the model structure (temperature versus gas pressure) of a typical oxygen-rich giant $\left(T_{\text {eff }}=3100 \mathrm{~K}, \log (g)=-0.5\right.$, and $\left.\mathrm{C} / \mathrm{O}=0.43\right)$. The tickmarks indicate increasing optical depths in steps of $\log \tau_{\text {Ross }}=0.75$ from the value $\log \tau_{\text {Ross }}=-5.5$ in the surface layer.

For the giants, the $\mathrm{C} / \mathrm{O}$ ratio will increase after the helium shell flash phase when freshly produced ${ }^{12} \mathrm{C}$ is mixed to the surface. This will gradually decrease the amount of available free oxygen, after the formation of $\mathrm{CO}$, and will eventually change the model structure and spectral appearance completely as $\mathrm{C} / \mathrm{O}$ approaches and pass unity. At slight increases of $\mathrm{C} / \mathrm{O}$ the effect on the model structure is nevertheless negligible. Even for $\mathrm{C} / \mathrm{O}=0.87$ the gas pressure in the surface of a model with $T_{\text {eff }}=3100 \mathrm{~K}$ is decreased with less than 0.3 dex (caused 

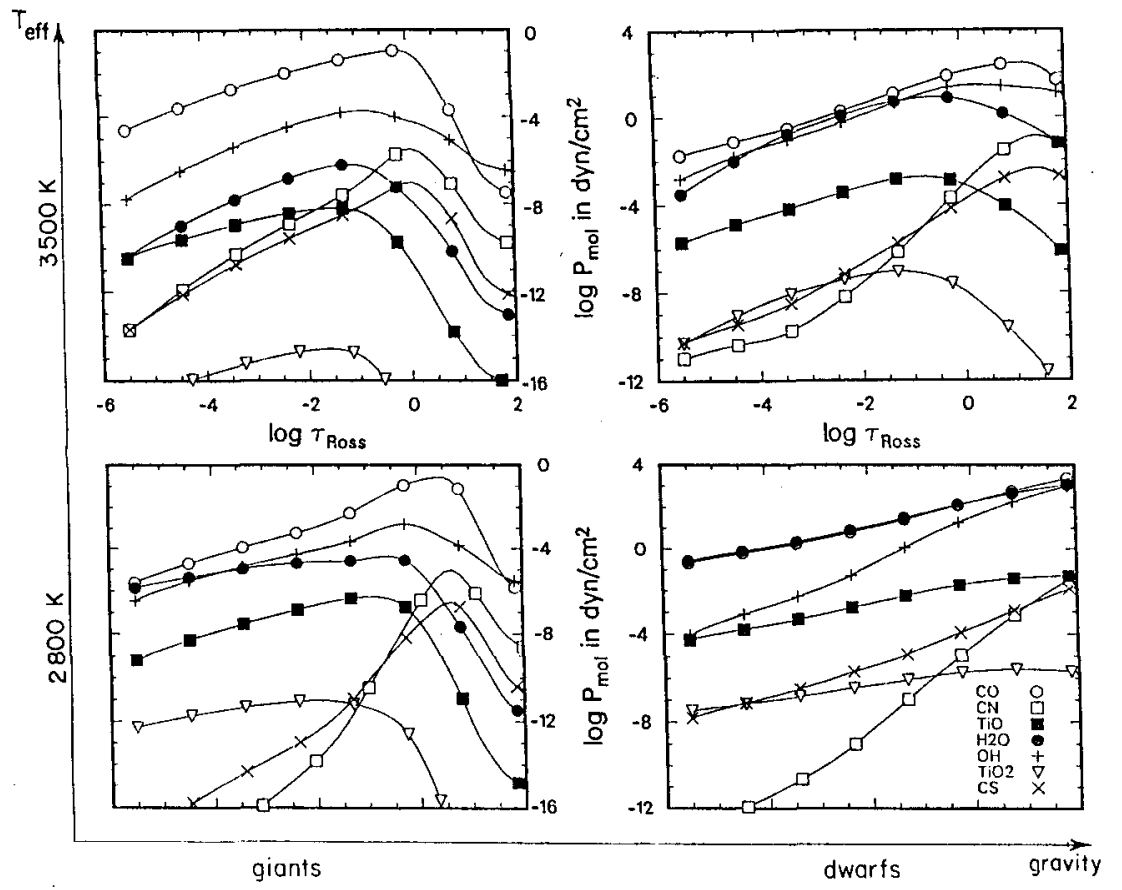

Fig. 3. The partial pressure of various molecules in the atmosphere of four oxygen-rich stars in the "molecular regime". The two left panels show typical giants $(\log (g)=-0.5)$ and the two panels to the right in the figure show typical $\mathrm{M} d$ warfs $(\log (g)=+4.5)$. The two uppermost panels are for $T_{\text {eff }}=3500 \mathrm{~K}$ and the two lower panels are for $T_{\text {eff }}$ $=2800 \mathrm{~K}$.

by the decreased formation of $\mathrm{H}_{2} \mathrm{O}$ ) and the surface temperature increased with only $15 \mathrm{~K}$, compared to a corresponding model with $\mathrm{C} / \mathrm{O}=0.43$.

For stars of higher surface gravity (M dwarfs, cool white dwarfs, and brown dwarfs) $\mathrm{CO}, \mathrm{TiO}$, and $\mathrm{H}_{2} \mathrm{O}$ are still abundant, but the relative importance of water increases dramatically compared to the two other molecules. Effects of the molecular abundance in oxygen-rich models of different temperature and gravity are shown in Fig. 3. It is, for example, seen that at $T_{\text {eff }}=2800 \mathrm{~K}$ and $\log (g)=$ +4.5 (an $\mathrm{M}$ dwarf), the partial pressure of $\mathrm{H}_{2} \mathrm{O}$ equals the partial pressure of $\mathrm{CO}$ throughout the atmosphere. Even at $T_{\text {eff }}=3500 \mathrm{~K}$ it equals that of $\mathrm{CO}$ from $\log \tau_{\text {Ross }}=-3$ to -1 . $\mathrm{CN}$ and $\mathrm{H}^{-}$are of less importance in the high gravity objects than in the giants. As expected, the more complex molecules increase in importance for the high gravity objects. For example the partial pressure of $\mathrm{TiO}_{2}$ is only 3 to 4 orders of magnitude below that of $\mathrm{TiO}$ in the $\log (g)=4.5$ models compared to up to 8 orders of magnitude below that of $\mathrm{TiO}$ in the warmer low gravity models. Also $\mathrm{CaOH}, \mathrm{CaH}, \mathrm{FeH}, \mathrm{CO}_{2}, \mathrm{CH}_{4}$, and collision induced absorption are candidates of being important opacity sources in the cool high gravity objects, and some of them are described in detail in other chapters of 
this book. Their inclusion is still in a more exploratory phase than the opacity sources in the giant models, and seems to impose new challenges. Molecules that may still be missing in the opacity of our red giant models include $\mathrm{SiO}$, $\mathrm{CS}, \mathrm{OH}, \mathrm{MgH}$ and other hydrides. Although at least some of these molecules have been included in models computed with other codes than the Marcs code (see particularly Brown et al. 1989), their effect on the model structure has not explicitly been studied, and the degree of completeness of the existing line lists for these molecules has not been analyzed either.

\section{Carbon-Rich Giant Stars}

When enough carbon is mixed into the atmosphere of a red giant star that the number ratio $\mathrm{C} / \mathrm{O}$ of carbon to oxygen exceeds unity, the star is a carbon star. Since $\mathrm{CO}$ is the most tightly bound of the molecules present in the atmosphere, all oxygen will be locked up in $\mathrm{CO}$. $\mathrm{TiO}$ and $\mathrm{H}_{2} \mathrm{O}$ (that dominates the opacity in the oxygen-rich red giants) are therefore almost completely absent in the carbon stars.

The carbon stars are more rich in the molecular variety than the oxygen-rich stars, due to the higher complexity of the carbon chemistry. At least 6 molecules are known to be vital for the structure of cool carbon stars $\left(\mathrm{CO}, \mathrm{CN}, \mathrm{C}_{2}, \mathrm{C}_{3}\right.$, $\mathrm{HCN}$, and $\mathrm{C}_{2} \mathrm{H}_{2}$ ), and it seems that even more than these 6 molecules are necessary for a good description of the photospheric opacity in the carbon stars. $\mathrm{CH}, \mathrm{CS}, \mathrm{NH}, \mathrm{C}_{2} \mathrm{H}, \mathrm{C}_{3} \mathrm{H}, \mathrm{SiC}_{2}$, and other molecules are likely candidates for this "missing" opacity. Typically, the introduction of the opacity from molecules (diatomics or polyatomics) in cool carbon stars where otherwise only continuum sources were considered, gives rise to a cooling of the surface layers of about $1000 \mathrm{~K}$, as is seen in Fig. 4 where the effect of various molecules on the model structure of two representative carbon stars are shown. As is seen from the figure, the diatomic molecules give rise to a cooling and contraction (increase of the gas pressure for given optical depth) of the atmosphere. The polyatomic molecules, on the other hand, again expands the atmosphere compared to the structure where only diatomics are included, and the final effect of all the molecules together is therefore to change drastically the temperature versus gas pressure structure, but to produce a less pronounced change in the gas pressure versus optical depth structure. In older models where no polyatomic molecules were included in the molecular opacity of the carbon stars, the temperature versus gas pressure structure (which is particularly relevant for the predicted spectrum, and therefore also for determination of the abundance, gravity, etc.) were actually further from the right structure than models with no molecules included in the opacity at all, as is seen from Fig. 4, whereas the less sensitive temperature versus optical depth structure were predicted better in the models with diatomic molecules than in the models completely without molecular opacities.

For the cooler carbon stars, polyatomic molecules dominate the opacity fairly deep into the atmosphere whereas diatomics have the highest partial pressure all the way to the surface in our warmer models. In a model with $\mathrm{C} / \mathrm{O}=1.05$ 

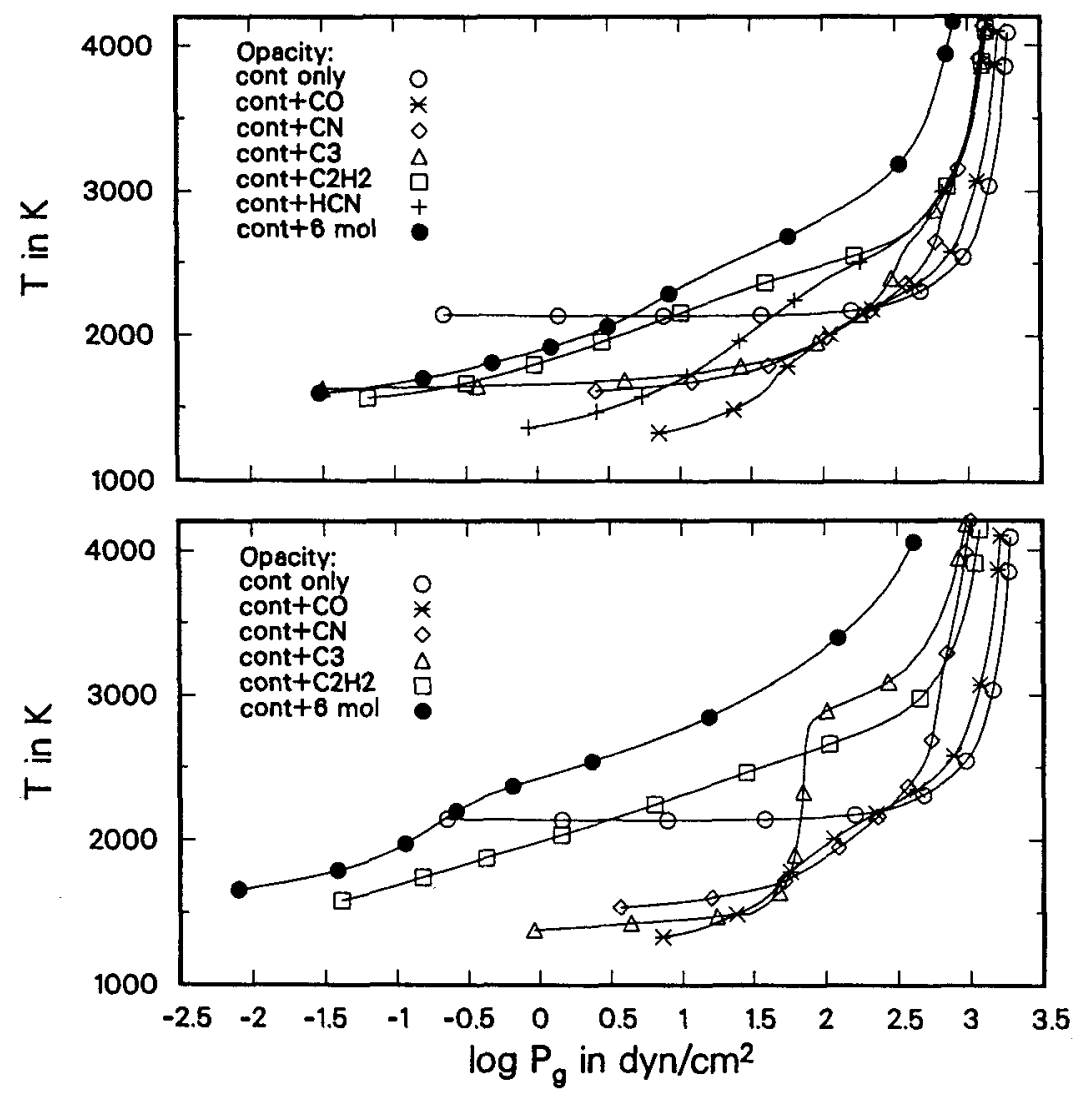

Fig. 4. Effects of $\mathrm{CO}, \mathrm{CN}, \mathrm{C}_{3}, \mathrm{HCN}$ and $\mathrm{C}_{2} \mathrm{H}_{2}$ on the model structure of two typical carbon-rich red giants of $T_{\text {eff }}=2800 \mathrm{~K}$ and $\log (g)=-0.5$, with $\mathrm{C} / \mathrm{O}=1.05$ (upper panel) and 2.0 (lower panel), respectively. Tickmarks as in Fig. 2. The response from inclusion of $\mathrm{C}_{2}$ (not shown) is very similar to that of $\mathrm{CN}$.

and $T_{\text {eff }}=2500 \mathrm{~K}, \mathrm{HCN}$ is the most abundant of the 6 molecules included in the opacity (apart from $\mathrm{CO}$ which has a very low absorption coefficient) from the surface and to the layer where $\tau_{\text {Ross }} \approx 1$. For a corresponding $T_{\text {eff }}=3500 \mathrm{~K}$ model, $\mathrm{CN}$ dominates the molecular pressure (apart from $\mathrm{CO}$ ) throughout the atmosphere. For the warmer stars, CS has a partial pressure higher than any of the 5 (CO excluded) through a substantial part of the atmosphere (particularly for the carbon stars with $\mathrm{C} / \mathrm{O}$ only slightly above 1 , and for low values of the gravity), but its opacity has not been included in the computations presented here (or in any other computations based on the Marcs code). As for CO, the band systems of $\mathrm{CS}$ are not as rich as those of $\mathrm{TiO}, \mathrm{C}_{2}$ and $\mathrm{CN}$, but due to the high partial pressure, its effects certainly deserves further investigation.

The increasing excess of carbon resulting from successive He-shell flashes, will leave more and more free carbon (after the formation of $\mathrm{CO}$ molecules) to form carbon-rich molecules. For this reason the $\mathrm{C}_{2}$ band strengths are traditionally 


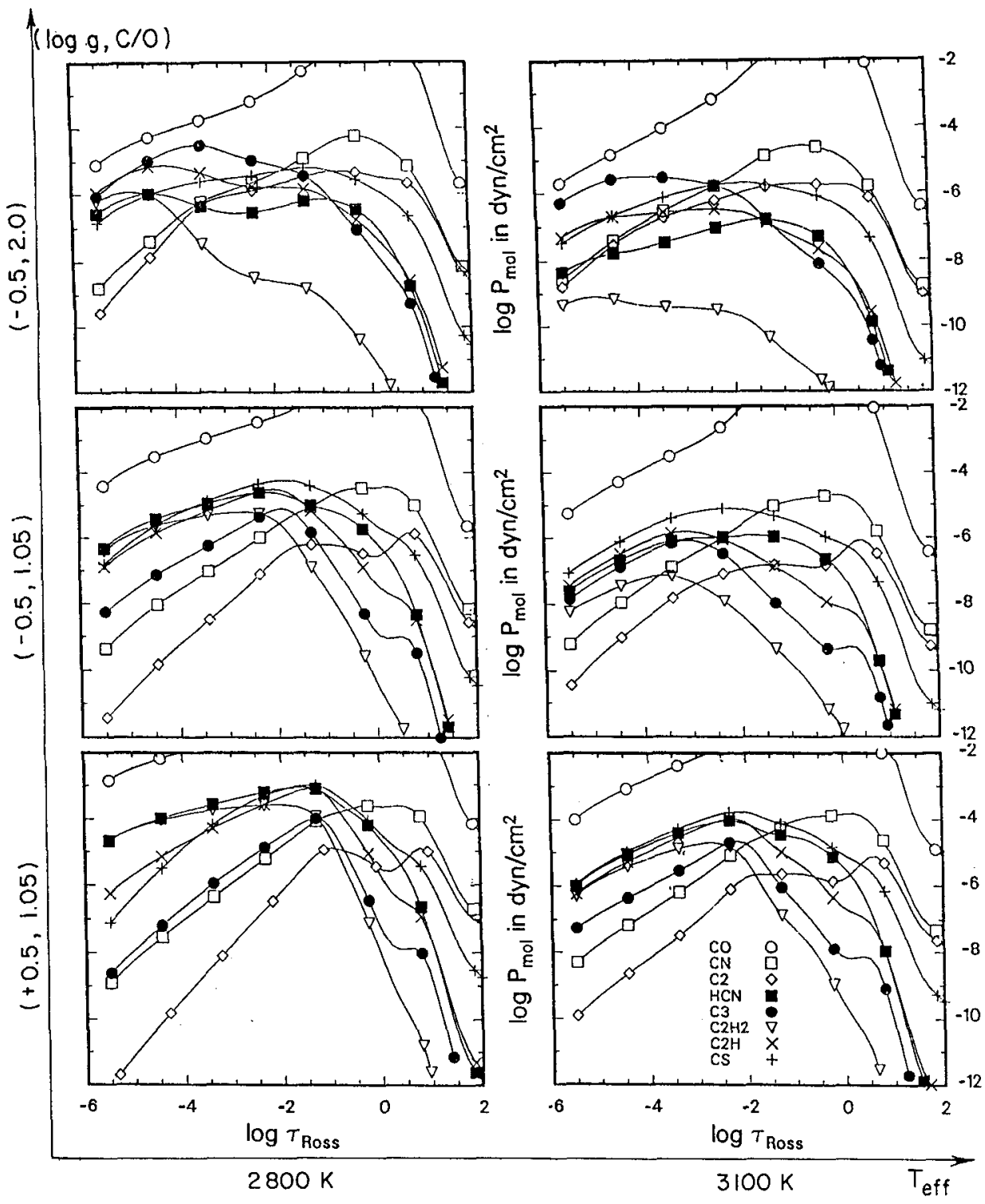

Fig. 5. The partial pressure of various molecules in the photosphere of six representative carbon stars of $T_{\text {eff }}=2800 \mathrm{~K}$ (left panels) and $T_{\text {eff }}=3100 \mathrm{~K}$ (right panels). From top to bottom the stars have $(\log (g), \mathrm{C} / \mathrm{O})=(-0.5,2.0),(-0.5,1.05)$, and $(+0.5$, 1.05), respectively. Tickmarks as in Fig. 2. 
used as an index for the $\mathrm{C} / \mathrm{O}$ ratio (this is the $j$ in the $\mathrm{C}_{i, j}$ classification scheme of carbon stars; see, e.g., Yamashita 1972). For a model with $T_{\text {eff }}=3100 \mathrm{~K}$ the partial pressure of $\mathrm{C}_{2}$ at $\tau_{\text {Ross }}=10^{-2}$ is 100 times smaller than that of $\mathrm{CN}$ when $\mathrm{C} / \mathrm{O}=1.05$, but it is less than a factor of 10 below $\mathrm{CN}$ for $\mathrm{C} / \mathrm{O}=$ 2.0. In the upper photosphere where the small polyatomic molecules form, the sensitivity to adjustmen ts in the model structure is nevertheless even bigger, and our models show the abundance of $\mathrm{C}_{3}$ to be considerably more sensitive to the $\mathrm{C} / \mathrm{O}$ ratio than the abundance of $\mathrm{C}_{2}$, but the bands due to $\mathrm{C}_{3}$ are predominantly in the less studied infrared spectral region, whereas the $\mathrm{C}_{2}$ bands are in the visual region accessible by use of CCDs and photographic plates. When $\mathrm{C} / \mathrm{O}$ increases from $\mathrm{C} / \mathrm{O}=1.05$ to $\mathrm{C} / \mathrm{O}=2.0$ for a $T_{\text {eff }}=3100 \mathrm{~K}$ model, the partial pressure of $\mathrm{C}_{3}$ increases with a factor of 100 more than the partial pressures of $\mathrm{C}_{2}$, as is readily seen in Fig. 7 (in the next section). Also $\mathrm{C}_{2} \mathrm{H}$ and $\mathrm{C}_{2} \mathrm{H}_{2}$ are strongly increasing functions of the $\mathrm{C} / \mathrm{O}$ ratio, whereas $\mathrm{NH}, \mathrm{CN}$, and $\mathrm{HCN}$ are remarkably unaffected by changes in the $\mathrm{C} / \mathrm{O}$ ratio, and the partial pressure of $\mathrm{CS}$ even decreases slightly when $\mathrm{C} / \mathrm{O}$ increases. Among the polyatomics, $\mathrm{C}_{3}$ has its main influence for $T_{\text {eff }} \approx 3100 \mathrm{~K}$ and for high $\mathrm{C} / \mathrm{O}$ ratio and low gravity, whereas $\mathrm{C}_{2} \mathrm{H}_{2}$ increase in importance for lower temperatures and/or high $\mathrm{C} / \mathrm{O}$. For $\mathrm{C} / \mathrm{O}$ close to unity, the partial pressure of $\mathrm{C}_{2} \mathrm{H}_{2}$ and $\mathrm{C}_{3}$ are both relatively low, and HCN is therefore the dominating polyatomic opacity source for the "carbon-poor" carbon stars. At $\mathrm{C} / \mathrm{O}$ approaching 2 (which is a very high $\mathrm{C} / \mathrm{O}$ ratio at least for carbon stars in the solar vicinity) the partial pressures of both $\mathrm{C}_{3}$ and $\mathrm{C}_{2} \mathrm{H}$ are considerably higher than those of $\mathrm{HCN}$ and $\mathrm{C}_{2} \mathrm{H}_{2}$. It imposes a serious problem for reliably modelling of the carbon-rich carbon stars that the monochromatic absorption coefficient of $\mathrm{C}_{2} \mathrm{H}$ is still unknown in a form useful for astrophysics (see Peyerimhoff this volume), and therefore considered to have zero opacity in all existing models.

The general effect on the model structure when increasing the $T_{\text {eff }}$ and keeping the other fundamental parameters constant, is to expand and heat the surface layers. The same trend appears when $\mathrm{C} / \mathrm{O}$ is increased.

Carbon stars with higher gravity $(\mathrm{dC}, \mathrm{CH}$, and $\mathrm{Ba}$ stars) than $\mathrm{AGB}$ red giant carbon stars can be understood as formed from mass transfer in binary systems. Exploratory models have been constructed for their atmospheres (Gass et al. 1988 and Kipper 1992, see also Liebert this volume). Molecules like $\mathrm{CH}_{4}, \mathrm{CaH}$, $\mathrm{FeH}$ and/or others might be important opacity candidates in such stars. Figure 5 gives an impression about which direction the changes will take if models of the higher gravity carbon stars are to be constructed. The higher the gravity the more likely will the formation of larger molecules be. For example the abundance of $\mathrm{C}_{2} \mathrm{H}_{2}$ relative to $\mathrm{C}_{2} \mathrm{H}$ or relative to $\mathrm{HCN}$ will be an increasing function of gravity, as is also easily seen in Fig. 5, and generally the effect of polyatomic molecules will increase relative to the diatomics when the gravity increases. It is also seen that the traditional measures of the carbon abundance, $\mathrm{C}_{2}$ (and $\mathrm{C}_{3}$ ), are dependent on gravity too, in the sense that their partial pressures relative to $\mathrm{CN}$ and $\mathrm{CH}$, or $\mathrm{HCN}$, is a decreasing function of gravity, which of course impose a problem to direct use of the two dimensional carbon star classification scheme 
( $\mathrm{C}_{i j}$, with $j$ based on the $\mathrm{C}_{2}$ band intensities, and with $i$ based on the $\mathrm{NaD}$ atomic line intensities which are also gravity dependent) to the dwarf stars.

\section{S-Type Stars}

Beside the oxygen-rich and the carbon-rich red giant stars, there are also the less common S-type stars. These are classified from having strong $\mathrm{ZrO}, \mathrm{VO}, \mathrm{LaO}$, and YO spectral bands. The name $S$ stars is historical from the time the stars were classified into the spectral groups A, B, C, D, ...., but it happens to be so, that the spectra of the $S$ stars are also rich in s-process elements. Let $N(X) / N_{6}(S i)$ be the number of atoms $\mathrm{X}$ per $10^{6} \mathrm{Si}$ atoms. For solar composition the number of oxygen atoms per $10^{6} \mathrm{Si}$ atoms, after the CO formation, is $[\mathrm{N}(\mathrm{O})-\mathrm{N}(\mathrm{C})] / \mathrm{N}_{6}(\mathrm{Si})$ $=1.3710^{7}$. $\mathrm{Si}$ is the most abundant atom that can form diatomic oxide with a dissociation energy higher than that of $\mathrm{TiO}$. Since $\mathrm{N}(\mathrm{Ti}) / \mathrm{N}_{6}(\mathrm{Si})$ is as low as 2400 , there is 10 times more free oxygen atoms than $\mathrm{Si}$ and $\mathrm{Ti}$ atoms to form $\mathrm{SiO}$ and $\mathrm{TiO}$. When $\mathrm{C} / \mathrm{O}$ increases and more oxygen is bound into $\mathrm{CO}$, $[\mathrm{N}(\mathrm{O})-\mathrm{N}(\mathrm{C})] / \mathrm{N}_{6}(\mathrm{Si})$ decreases and approaches 1 for $\mathrm{C} / \mathrm{O}=0.96$. At this value of $\mathrm{C} / \mathrm{O}$ the amount of $\mathrm{TiO}$ is therefore no longer determined by the abundance of $\mathrm{Ti}$, but by the amount of available free oxygen. The two dominant oxygen-rich molecular absorbers ( $\mathrm{TiO}$ and $\mathrm{H}_{2} \mathrm{O}$ ) will therefore decrease in amount, which will cause the atmosphere to shrink, which will in turn cause the gas pressure to increase. Since both $\mathrm{ZrO}, \mathrm{LaO}$, and $\mathrm{YO}$ have higher dissociation energies than $\mathrm{TiO}$, the partial pressure of these molecules will, to a start, increase. The result will be that the intensity of the bands of these molecules will increase strongly compared to the intensity of the $\mathrm{TiO}$ bands. When $\mathrm{ZrO}$ bands are visible the star is called an S star, and the point when the intensity of the $\mathrm{ZrO}$ and the $\mathrm{TiO}$ bands are equal is expected to correspond to $\mathrm{C} / \mathrm{O} \approx 0.96$ (Jaschek \& Jaschek 1990 ). It is generally assumed that there is an evolutionary sequence from the oxygen-rich to the S-type to the carbon-rich red giants, although details in this simple scenario have several times been criticized (e.g., Iben \& Renzini 1983, Lundgren 1988).

From the point of view of molecular opacities the S-type stars are an interesting challenge, because both $\mathrm{TiO}$ and $\mathrm{H}_{2} \mathrm{O}$ are disappearing gradually, and the carbon-rich molecules are not yet formed. This gives rise to a "molecular zoo" those members have not yet been fully identified, and many molecules may act together to define the opacity. To judge from the spectra, the elemental abundances, and the dissociation energies (see Table 1), $\mathrm{ZrO}, \mathrm{LaO}, \mathrm{YO}, \mathrm{VO}, \mathrm{FeH}$, $\mathrm{MgH}, \mathrm{CaH}, \mathrm{ZrS}$, and $\mathrm{SiS}$ may all play a role for the atmospheric structure of $\mathrm{S}$ stars. Only few of these molecules have yet been studied in the sense that reasonably complete line lists exist. For the important opacities of $\mathrm{ZrO}, \mathrm{YO}$, and $\mathrm{FeH}$, an extensive analysis has been performed as part of the Berkeley program (see Davis this volume), and a line list has been constructed for $\mathrm{ZrO}$ and $\mathrm{YO}$, which shows the $\mathrm{ZrO}$ to be the most important heir (it has many lines in several electronic systems, and high $f$-values) of $\mathrm{TiO}$ when the abundance of $\mathrm{TiO}$ decreases. 
We can presumably learn about a number of qualitative effects in the S-type star atmospheres from studying models based on only the molecular opacities included in the carbon-rich and oxygen-rich models $\left(\mathrm{CO}, \mathrm{CN}, \mathrm{C}_{2}, \mathrm{TiO}, \mathrm{HCN}\right.$, $\mathrm{C}_{3}, \mathrm{C}_{2} \mathrm{H}_{2}, \mathrm{H}_{2} \mathrm{O}$ ), although the effects for $\mathrm{C} / \mathrm{O}$ close to 1 , of course can only be taken as indicative. From such models the first surprise is maybe to discover how relatively insensitive the $M$-type atmosphere is to changes in the $\mathrm{C} / \mathrm{O}$ ratio until $\mathrm{C} / \mathrm{O}$ approaches very close to unity. When $\mathrm{C} / \mathrm{O}$ change from 0.43 (the solar value) to 0.95 the gas pressure and temperature in the surface change with 0.5 dex and $75 \mathrm{~K}$, respectively, and the physical size of the atmosphere decreases with only $15 \%$ for a test-model with $T_{\text {eff }}=3100 \mathrm{~K}$ and $\log (g)=-0.5$. This reflects that there is still more free oxygen after $\mathrm{CO}$ and $\mathrm{SiO}$ formation than there is elemental Ti (for solar elemental abundances). The effect is comparable to the effect of excluding (from the opacity in M-type giants) those of the weak lines of the $\mathrm{H}_{2} \mathrm{O}$ rotation-vibration system that makes up only $4 \%$ of the $\mathrm{H}_{2} \mathrm{O}$ absorption coefficient (see Fig. 1). Models based on an absorption coefficient of $\mathrm{H}_{2} \mathrm{O}$ with $4 \%$ uncertainty will consequently not be able to distinguish the physical properties of an M-type giant with $\mathrm{C} / \mathrm{O}=0.43$ from an S-type giant with $\mathrm{C} / \mathrm{O}=0.95$ (but the chemical properties are of course calculated better despite of this).
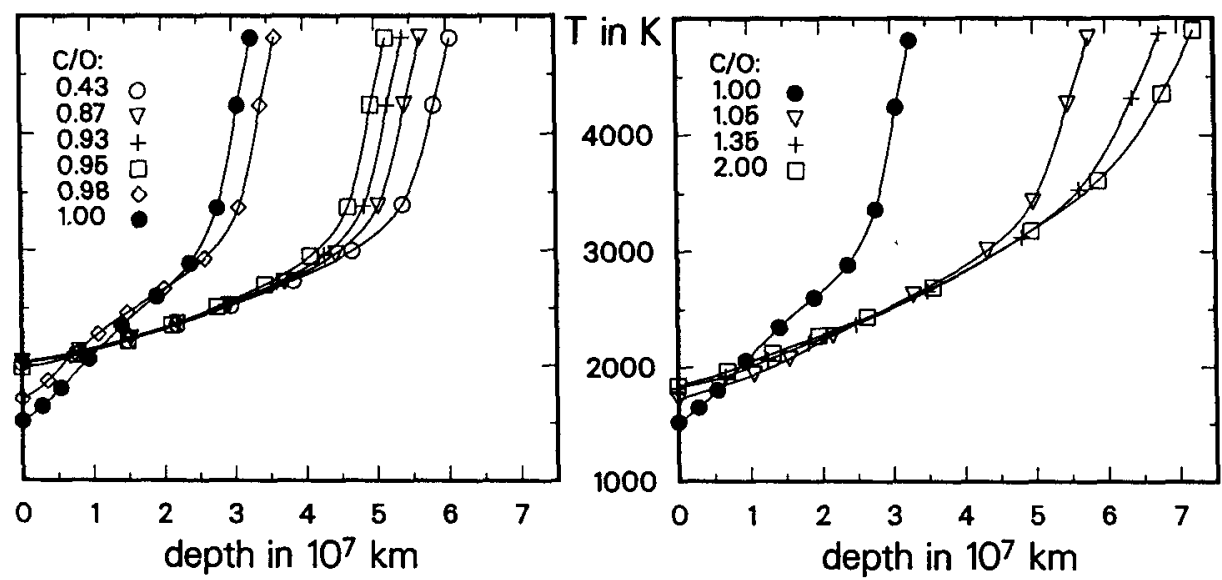

Fig. 6. The geometrical size of the atmosphere of red giant models of $T_{\text {eff }}=3100$, $\log (g)=-0.5$, and various $\mathrm{C} / \mathrm{O}$ ratios ranging from $\mathrm{C} / \mathrm{O}=0.43$ to $\mathrm{C} / \mathrm{O}=2.0$ (as indicated with the legend). It is seen that when $\mathrm{C} / \mathrm{O}$ increase beyond the Solar value, the atmosphere first shrinks because of the disappearance of $\mathrm{TiO}$ and $\mathrm{H}_{2} \mathrm{O}$, until the star is an $\mathrm{S}$ star with $\mathrm{C} / \mathrm{O} \approx 1$ (left panel), but then rapidly increases in size again when $\mathrm{C} / \mathrm{O}>1$ (right panel) and carbon-rich molecules $\left(\mathrm{CN}, \mathrm{C}_{2}, \mathrm{HCN}, \mathrm{C}_{2} \mathrm{H}_{2}, \mathrm{C}_{3}\right.$ ) form. 


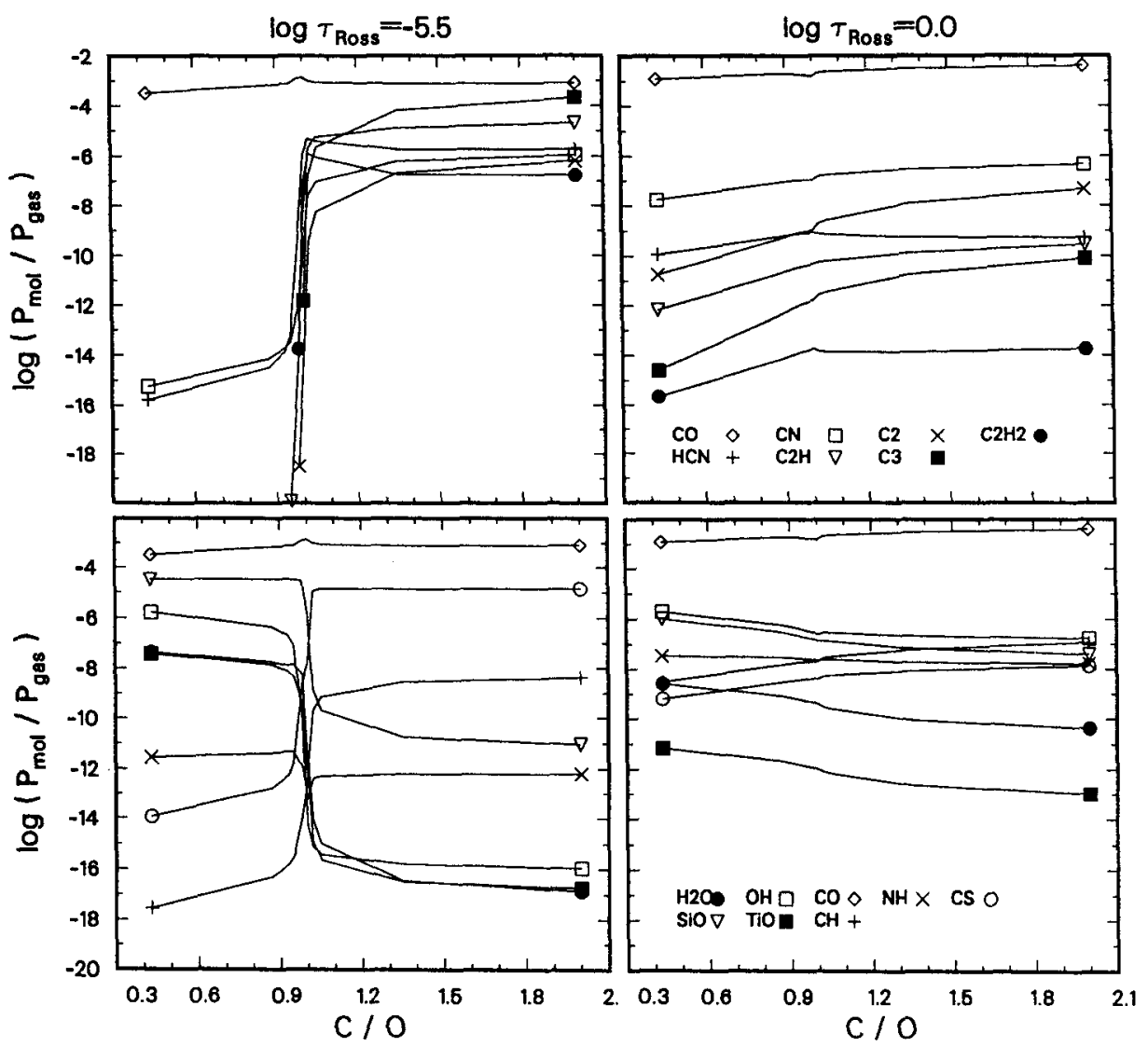

Fig. 7. The changes in the partial pressure of various molecules is large when $\mathrm{C} / \mathrm{O}$ change from below to above 1, particularly in the upper photosphere (left panel) and less pronounced in the lower part of the photosphere where the molecules that are traditionally used as spectroscopic indicators of the $\mathrm{C} / \mathrm{O}$ ratio, are formed (right panel).

When changing the $\mathrm{C} / \mathrm{O}$ ratio from 0.95 to 1.0 there occurs a dramatic readjustment of the model structure. For a $T_{\text {eff }}=3100 \mathrm{~K}$ model, the surface cools with $500 \mathrm{~K}$, and the size of the atmosphere is reduced with nearly a factor of two, as is seen in Fig. 6. This effect may of course partly be due to lacking knowledge of the opacities of the molecules that show strong features in the spectrum, but qualitatively the effect is likely to be correct, because the strong contraction basically is due to the lack of polyatomic molecules in S-type stars - from an observational as well as from a theoretical point of view. There is a dramatic change in the relative partial pressure of the oxygen and the carbon 
bearing molecules when $\mathrm{C} / \mathrm{O}$ increases from 0.95 to 0.98 , as is seen in Fig. 7. The number-ratio of $\mathrm{H}_{2} \mathrm{O}$ and $\mathrm{HCN}$ molecules changes with 11 orders of magnitude in a red giant model atmosphere with $T_{\text {eff }}=3100 \mathrm{~K}$ and $\log (g)=-0.5$ when $\mathrm{C} / \mathrm{O}$ changes from 0.95 to 1.0 . At $\mathrm{C} / \mathrm{O}=0.95$ the partial pressure of $\mathrm{H}_{2} \mathrm{O}$ in the surface layers is 5 orders of magnitude higher than that of HCN. At $\mathrm{C} / \mathrm{O}=0.98$ it is only 1 order of magnitude above, and at $\mathrm{C} / \mathrm{O}=1.0$ it is 6 orders of magnitude below HCN. From $\mathrm{C} / \mathrm{O}=1.0$ to $\mathrm{C} / \mathrm{O}=2.0$ the partial pressure of $\mathrm{HCN}$ stays approximately constant, while those of the more carbonrich molecules increase rapidly. For example the partial pressure of $\mathrm{C}_{3}$ increases with nearly 7 orders of magnitude. It is these enormous changes in the partial pressures of the polyatomic molecules that are responsible for the big changes in the surface gas pressure, and in the size, of the red giants with $\mathrm{C} / \mathrm{O} \approx 1$, and these effects are therefore relatively independent of the inclusion of the proper diatomic S-type opacities ( $\mathrm{ZrO}, \mathrm{LaO}, \mathrm{YO}, \mathrm{FeH}$, and $\mathrm{VO}$ ). The main changes in the partial pressures of the diatomic molecules included in our computations are a strong decrease in $\mathrm{TiO}$ when $\mathrm{C} / \mathrm{O}$ approaches and pass unity, and a corresponding increase in the amount of $\mathrm{CN}$ and $\mathrm{CH}$. The ratio between $\mathrm{TiO}$ and $\mathrm{CN}$ (or $\mathrm{CH}$ ) changes with 7 orders of magnitude when $\mathrm{C} / \mathrm{O}$ increases from 0.95 to 1.0 (and this change must be expected to increase when $\mathrm{ZrO}, \mathrm{VO}, \mathrm{YO}$, and $\mathrm{LaO}$ are introduced into the opacities, because they use some of the oxygen otherwise available for $\mathrm{TiO}$ ).

\section{Summary}

Molecules are particular important in the photosphere of stars in the effective temperature interval from about $3500 \mathrm{~K}$ to $2500 \mathrm{~K}$ (and below). This temperature regime include the cool red giants as well as the $\mathrm{M}$ dwarfs, brown dwarfs, and cool white dwarfs. I have described the SCAN data base of 60 million molecular lines from $\mathrm{CN}$, TiO, $\mathrm{CH}, \mathrm{HCN}, \mathrm{C}_{2} \mathrm{H}_{2}, \mathrm{C}_{3}$, and $\mathrm{H}_{2} \mathrm{O}$, and analyzed the effect of the opacities constructed from these data (and data from $\mathrm{CO}$ and $\mathrm{C}_{2}$ ) on models of cool stellar atmospheres. 150 new models were computed by use of the Marcs code and with the molecular input data varied in a systematic way in order to understand the effect of the individual molecules. Typical changes in the model structure of a cool red giant when molecules are included into the opacity is a cooling in the surface layer of about $1000 \mathrm{~K}$. The diatomic molecules cause a contraction of the atmosphere, whereas a typical effect of polyatomic molecules is to expand the atmosphere considerably. Marked changes have occurred during recent years in the obtained model structure, and this will probably be the case for some more years when additional and better molecular data become available, and particularly for the $S$ stars and the dwarfs, the models are still exploratory. The strong interaction between the molecules was stressed, and potential candidates for "missing" opacities were suggested. 


\section{References}

Anders E., Grevesse N., 1989, Geochim. Cosmochim. Acta, 53, 197

Anders E., Zinner E., 1993, Meteoritics, 28, 490

Brown J.A., Johnson H.R., Alexander D.R., Cutright L.C., Sharp C.M., 1989, Astrophys. J. Suppl., 71, 623

Chase M.W., Davies C.A., Downey J.R., Frurip D.J., McDonald R.A., Syverud A.N. (eds.), 1984, JANAF Thermochemical Tables, 3.edition

Colket M.B., 1984, J. Quant. Spectrosc. Radiat. Transfer, 31, 7

Costes M., Naulin C., Dorthe G., 1990 Astron. Astrophys., 232, 270

de Jager C., Nieuwenhuijzen H., van der Hucht K. A., 1988, Astron. Astrophys. Suppl., 72, 259

Eriksson K., Gustafsson B., Jørgensen U.G., Nordlund A.., 1984, Astron. Astrophys., 132, 37

Gustafsson B., Bell R.A., Eriksson K., Nordlund A., 1975, Astron. Astrophys., 42, 407 Gass H., Liebert J., Wehrse R., 1988, Astron. Astrophys., 189, 194

Gustafsson B., 1989, Ann. Rev. Astron. Astrophys., 27, 701

Huber K.P., Herzberg G., 1979, Constants of Diatomic Molecules, Van Nostrand, N.Y.

Iben I., Renzini A., 1983, Ann. Rev. Astron. Astrophys., 21, 271

Jaschek C, Jaschek M., 1990, The Classification of Stars, Cambridge Univ. Press

Johnson H.R., 1986, In: The M-type stars, H.R.Johnson\&F.R.Querci (eds.), NASA SP-492, p. 323

Jørgensen U.G., 1990, Astron. Astrophys., 232, 420

Jørgensen U.G., 1991, Astron. Astrophys., 246, 118

Jørgensen U.G., 1992, Rev. Mexicana Astron. Astrof., 23, 49

Jørgensen U.G., 1993, Astron. Astrophys., in press

Jørgensen U.G., Almlöf J., Gustafsson B., Larsson M., Siegbahn P., 1985, J. Chem. Phys., 83, 3034

Jørgensen U.G., Almlöf J., Siegbahn P., 1989, Astrophys. J., 343, 554

Jørgensen U.G., Jensen P., 1993, J. Mol. Spectrosc., 161, 219

Jørgensen U.G., Jensen P., Sørensen G.O., 1994, In: P.Thejll\&U.G.Jørgensen (eds.), Poster Session Proceedings of IAU Coll.146, Copenhagen University, p. 51

Jørgensen U.G., Johnson H.R., 1992, Astron. Astrophys., 265, 166

Jørgensen U.G., Johnson H.R., Nordlund $\AA$, 1992, Astron. Astrophys., 261, 263

Jørgensen U.G., Larsson M., 1990, Astron. Astrophys. 238, 424

Kipper T., 1992, Baltic Astronomy, 1, 181

Krupp B.M., Collins J.G., Johnson H.R., 1978, Astrophys. J., 219, 963

Kurucz R.L., 1979, Astrophys. J. Suppl., 40, 1

Lundgren K, 1988, Astron. Astrophys., 200, 85

Piñeiro A.L., Tipping R.H., Chackerian C.Jr., 1987, J. Mol. Spec., 125, 91

Plez B., Brett J.M., Nordlund $\AA$, 1992, Astron. Astrophys., 256, 551

Querci F., Querci M., Tsuji T., 1974, Astron. Astrophys., 31, 265

Richer H.B., Westerlund B.E., 1983 Astrophys. J., 264, 114

Tsuji T., 1964, Ann. Tokyo Astron. Obs., 9, no. 1

Tsuji T., 1973, Astron. Astrophys., 23, 411

Tsuji T., 1986, Ann. Rev. Astron. Astrophys., 24, 89

Yamashita Y., 1972, Ann. Tokyo Astron. Obs., 13, no. 3 